\title{
DE PROEFNEMING \\ VAN DE SURINAME HOEVE MAATSCHAPPIJ \\ DOOR
}

H. G. BRANDON

Op 21 Maart 1934 kwamen de heeren H. G. Brandon, G. J. baron van Hoevell en $\mathrm{Ph}$. Siebers in Suriname aan, om, samenwerkende onder de firma Suriname Hoeve Maatschappij, een poging te ondernemen, teneinde in de praktijk vast te stellen, of met de door den heer Brandon bepleite cultuurwijze met toepassing van moderne landbouwwerktuigen, getrokken door ossen, een loonend hoevebedrijf met rijst en eventueel mais als hoofdproducten, bestemd voor export naar Nederland, zou kunnen worden opgebouwd.

Een zorgvuldige becijfering had uitgewezen, dat voor de uitvoering van deze proefneming een kapitaal van $f 30000$,- - noodig was, rekenende op goeden, vruchtbaren grond. De vereischte medewerking, om deze som bijeen te brengen, kon echter niet worden verkregen.

Overtuigd van de goede kansen van hun denkbeeld en gedreven door het groote actueele belang en de beteekenis, die een geslaagde verwezenlijking daarvan zou hebben, werd besloten het erop te wagen, de poging te ondernemen met het minimum bedrag van f 10000,-_, dat een begin met kans op voortzetting mogelijk maakte.

De opzet bij een zoo krap gemeten kapitaal noopte tot dadelijke vermenging van de eigenlijke, vooraf te gane, oriënteerende proefneming en het daarop te volgen opzetten van het definitieve bedrijf en bracht noodzakerwijze mede, dat op een dekkende bedrijfsuitkomst reeds gedurende het eerste bedrijfsjaar moest worden gerekend.

Daartoe werd vereischt bij de lage prijzen van padi, rijst en mais op de binnenlandsche markt, waarop de aanvankelijke afzet van de producten uiteraard zou moeten geschieden, dat een geslaagd eerste oogstjaar van minstens $100 \mathrm{HA}$. werd verkregen, over twee oogsten gerekend. 
De mogelijkheid hiervan werd aangetoond door het met zorg en voorzichtigheid opgemaakte bedrijfsschema, waarbij het aannemelijke prestatievermogen van de gekozen werktuigen, getrokken door ossen, en het voor Surinaamschen kleigrond gewone gemiddelde aan padibeschot als becijferingsnormen hadden gediend

De proefneming omvatte dus twee wel te onderscheiden afzonderlijke onderdeelen:

1e. te onderzoeken of de werkwijze inderdaad praktisch uitvoerbaar was en resultaten opleverde, die de mogelijkheid van het verwerven daarmede van een regelmatig loonend bedrijf vaststelde;

2e. het opbouwen en verwezenlijken van een dergelijk hoevebedrijf.

Het eerste, zuiver oriënteerende, gedeelte van de proefneming ter empirische vaststelling van de bedrijfsnormen en andere bedrijfsgegevens is thans als afgeloopen te beschouwen en is volkomen geslaagd, aangezien de mogelijkheid om op de gedachte wijze loonend rijst te produceeren afdoende is vastgesteld.

Gedurende de geheele proefnemingsperiode van thans meer dan 28 maanden werden in totaal ca. $136 \mathrm{HA}$. oppervlakte onder alle mogelijke condities van den bodem en van het weer en met alle soorten werktuigen bewerkt, machinaal ingezaaid of met bibit beplant, machinaal en met de hand geoogst.

Gegrond op deze ruime praktijk zijn voor de rechtstreeksche cultuurkosten de ondervolgende gemiddelden als vaststaande normen verkregen, welke in verband met de in alle opzichten zeer moeilijke en ongeacheveerde omstandigheden, waaronder gewerkt is, als hooge maxima mogen gelden. Inderdaad zijn reeds in de praktijk belangrijk lagere uitkomsten verkregen, die, naarmate de organisatie van het bedrijf vervolmaakt wordt, meer en meer zullen voorkomen en als normale zullen gelden.

Voor de eerste keer, nadat het terrein ontdaan is van de begroeiïng, stompen en wortels, en de grond met de werktuigen bewerkt kan worden, zoomede machinaal gezaaid en geoogst kan worden, komen bij droge bewerking de kosten van ploegen, eggen en egaliseeren van den grond, zaaien, wieden en oogsten te staan op $f 29,50$ per HA., en indien de grond nat bewerkt wordt, niet gezaaid, doch met bibit beplant wordt, op $/ 37$, - .

Voor een akkeraanplant, d.w.z. de normale bedrijfstoestand, 
nadat de grond de eerste - en eventueel nog een tweede - bewer ing heeft ondergaan en van alle obstructies is ontdaan, zijn de kosten van $1 \mathrm{HA}$. padi-oogst bij droge bewerking en machinaal zaaien $f I 8,80$, en bij natte bewerking en bibit planten $f 26,50$.

Deze bedragen zijn uitsluitend loonkosten.

De gemiddelde rechtstreeksche cultuurkosten bij normaal bedrijf zijn dus $(f 18,80+f 26,35): 2=$ afgerond $f 23$,- per HA. $\left.{ }^{1}\right)$

Het is onvermijdelijk gebleken bij de wisselvalligheid van het weer, met onberekenbare afwisseling van korte periodes van droog en regenachtig weer, dat zoowel een droge als de natte cultuurwijze moet worden toegepast. Er zal echter steeds naar gestreefd moeten worden zooveel mogelijk in droge bewerking ingeplant te krijgen.

Naast de rechtstreeksche cultuurkosten staan de algemeene kosten. Onder deze laatste kosten komen de posten van de huishouding van den hoeveplanter, het onderhoud van de ossen,

1) Volgens betrouwbare en controleerbare gegevens van het bedrijf van $\mathrm{Br}$. Indische kleinlandbouwers in den omtrek van Station Domburg zijn de kosten van $1 \mathrm{HA}$. padi productie, berekend in dagloonen van $f 0,60$ voor een man en $f 0,40$ voor een vrouw, en taakloonen, zooals deze kleinlandbouwers inderdaad voor gehuurde krachten betalen en voor zich zelf verlangen:

2 man-dagen voor aanleg bibitbed. . . . . . . . . . . t 1,20 60 ct. per vierk. ketting wieden . . . . . . . . . . . . . $f 15$, $60 \mathrm{ct}$ per vierk. ketting bibitplanten . . . . . . . . . . . $f 15,-$ 40 ct. per vierk. ketting wieden $\mathrm{i} / \mathrm{d}$ padi. . . . . . . . . . $f 10$, $60 \mathrm{ct}$. per vierk. ketting snijden en stapelen van de padi . . $f 15$, gem. 5 balen dorschen per man per dag en 40 balen per HA. $f \quad 4,80$ gem. 5 balen wannen per dag per vroaw. . . . . . . . . $f 3,20$ transport 40 balen. . . . . . . . . . . . . . . . . . . $f 1,20$ $f 65,40$

grondhuur . . . . . . . . . . . . . . . . . . . . $\frac{f 10,-}{f 75,40}$

Opbrengst 3000 K.G. padi à 2 ct. per KG. $f 60,-$.

Aannemende, dat voor de eigen voeding een kleinlandbouwersgezin, bestaande uit man, vrouw en drie kinderen jaarlijks 600 KG. rijst noodig heeft, moet voor den oogst $1000 \mathrm{KG}$. padi daartoe aangehouden worden.

De overblijvende $2000 \mathrm{KG}$. padi, bestemd om te voorzien in de behoefte van het niet produceerende deel van de consumenten, dient naar redelijke billijkheid het loon en de kosten van den procucent minstens op te brengen, dus $f 75,-$. M.a.w. de rijstcultuur is voor den kleinlandbouwer pas loonend te achten bij een padiprijs van $3 \frac{3}{4} \mathrm{ct}$. à $4 \mathrm{ct}$ per KG., correspondeerende met een rijstprijs van $\mathrm{f} 8$, - voor den groothandel en $f$, - à $f 10$, - voor den kleinhandel. 
kosten van vast hulppersoneel als een motorist, die tevens ook wat van smeden en timmeren moet afweten, een mandoer om tijdelijk los werkvolk, wanneer noodig, te werven en hun werk te regelen, tevens het magazijnswerk en de verzorging van den oogst, administratiekosten, transportkosten, verzekeringen, bedrijfsbehoeften en dergelijke meer.

Deze algemeene kosten beloopen gemiddeld $f 3500$,- 's jaars en blijven tot een bepaalde grens vrijwel gelijk voor bedrijven van zeer uiteenloopend oppervlak, b.v. voor hoeven van 75 tot $150 \mathrm{HA}$.

De gemiddelde opbrengst van $1 \mathrm{HA}$. padi is veilig te stellen op 3000 KG. droge korrel. Deze opbrengst is voor alle padivarieteiten te verkrijgen en bij een geacheveerd bedrijf is er normaal meer kans, dat de opbrengst meer dan minder zal zijn.

De zoo te noemen kritische omvang van een rijsthoevebedrijf, d.w.z. de minimum grootte, waarbij het een dekkende uitkomst kan opleveren en als economisch veilig kan worden beschouwd, is afhankelijk van de te verwachten of aan te leggen marktwaarde van het product.

Is als praktisch laagste marktwaarde van padi 2 ct. per KG., of wel $f 4$,- per $100 \mathrm{KG}$. rijst, aan te nemen, dan is de waarde van $1 \mathrm{HA}$. padi-oogst gemiddeld $f 60$,-, zoodat bij gemiddelde cultuurkosten van $f 23$,- een marge van $f 37$,- overblijft, waaruit in de eerste plaats de algemeene kosten gevonden moeten worden. Hieruit volgt, dat er dan een hoeveelheid van ca. 300.000 KG padi, dus een oogst van ca. 100 HA., gewonnen moet worden, om de totale productiekosten op te brengen.

Er zal echter meer noodig zijn, teneinde kapitaalrente en een overschot te kunnen vinden, om tegenvallers te kunnen opvangen en uitzicht op eenige winst te verschaffen. Als veiligste kritische bedrijfsomvang is aldus af te leiden een hoeve met een aanplantoppervlakte van ca. I5० $\mathrm{HA}$. Een dergelijke hoeve levert een bedrijf op, dat op den duur zeker loonend is, alleen kwetsbaar door cultuur- of bedrijfscatastrofen. Het kapitaal, vereischt, om zulk een hoeve op te zetten, is $f 50000,-$ en na het derde jaar zijn, behalve kosten van levensonderhoud van den hoeveplanter, $6 \%$ rente op het kapitaal en een winstoverschot van ca. f 4000,- 's jaars te verwachten, bij verkoop van het product als rijst voor $f 4$,- - per $100 \mathrm{KG}$.

Kan superieure exportrijst voor de Nederlandsche markt geproduceerd worden, waarvan volgens de laatste berichten de noteering $f 10,50$ middenprijs is, dan is reeds bij een aanplantoppervlakte van $60 H A$. de kritische bedrijfsomvang bereikt en een veilig loonend hoevebedrijf verkregen. 
Dit is een volkomen reëele mogelijkheid, aangezien beschikt wordt over zaad van verschillende hier goed gedijende padivarieteiten, die zulke rijst opleveren. Het kapitaal, vereischt voor de opzet van een hoeve van deze omvang is ca. $f 25000$ à $f 30000$, na het derde jaar levensonderhoud, $6 \%$ kapitaalrente en ca $f 3000$,- winst opleverende.

Het bedrijf dient uitsluitend gebaseerd te zijn op één padi-oogst per jaar. Een tweede oogst in het tusschenseizoen NovemberApril verdient om verschillende cultuurtechnische redenen geen aanbeveling, terwijl de onberekenbaarheid van het weer in die periode voor elk veldgewas een onbegrensd risico oplevert, zoodat in die periode niet gerekend kan worden op verwerven van een loonenden oogst.

Ook ter compensatie hiervan zal daarom naast de rijstcultuur een staand gewas, b.v. sinaasappelen, als nevencultuur op de daartoe meer geeigende terreingedeelten moeten worden aangebracht.

Op reeds ontgonnen terrein vereischt zulks weinig kosten.

Mais is gebleken een veel moeilijker gewas te zijn dan rijst, en daarvan is niets te verwachten in extensieve cultuur anders dan als eerste ontginnings-catch crop. Voor regelmatige cultuur staat vast, dat een intensieve cultuurwijze toegepast zal moeten worden, vooral diepe drainage, uitvoerige grondbewerking en bemesting. Of dit een loonend resultaat zal opleveren, zal nog door een voldoende diepgaand en voortdurend experimenteel onderzoek van de praktische cultuur moeten blijken.

De eenige rijstaanplant kan bij toepassing van afwisselend droge en natte cultuur, naarmate van de wisselende weersomstandigheden, uitgestrekt worden van Januari tot en met Juni.

In de periode November-April dient echter wel een aanplant in den grond gebracht te worden ter voorkoming van verwildering en vervuiling van den akker met wieden, tevens om een goede cultuurconditie van den grond te bevorderen. Dit is dus een conserveeringsaanplant, waarbij niet beoogd wordt een oogst te winnen; wat echter binnengehaald wordt, is meegenomen. Boonensoorten zijn voor deze conserveeringsaanplant het meest aangewezen.

Regelmatige irrigatie is zeer goedkoop te verzekeren door pompen, hetgeen slechts als beperkte aanvullingsvoorziening vereischt is. Gedurende het loopende jaar b.v. is pompen in het geheel niet noodig geweest. Gebleken is, dat van Station Domburg bovenstroom af het water in de Suriname-rivier in de periode van behoefte altijd zoet is.

Voor de afwisselende droge en natte werkwijze leent de ossentractie zich bij uitnemendheid. 
Ossen als trekkracht voldoen zeer goed. Het is een bonte verzameling van allerlei kruisingen en types van domineerend Europeesche rassen, die in deze landen voorkomt. De dieren zijn niet speciaal op bepaalde eigenschappen gefokt en zeker niet als trekvee. Ze zijn als regel langzaam, doch betrekkelijk sterk. Ze zijn zeer sober en hebben een groote weerstand. Ziekte komt praktisch niet voor. Doch de dieren ondervinden periodiek zeer veel last van „muskietenwormen”, eigenlijk horsellarven, die zweeren veroorzaken, die soms buitengewone uitbreiding kunnen verkrijgen. Ook van persbulten, waarvoor een individueele vatbaarheid bestaat en die aanleiding kunnen zijn, dat de dieren geruimen tijd moeten uitvallen.

In het algemeen is echter de bedrijfszekerheid van ossen zeer groot.

De kosten van onderhoud van ossen beloopen $f 600$,- - per jaar voor 12 tot 24 ossen, hoofdzakelijk loon voor 2 stalknechts en voorts voor melasse ter bijmenging van het krachtvoer (normaal als afval verkregen bij de verwerking van het product), en eventueele geneeskundige hulp inbegrepen.

Met 12 span ossen kan per dag $1 \frac{1}{4}$ tot $2 \mathrm{HA}$. geheel bewerkt, ingeplant en geoogst worden, doch aannemende, dat met dit aantal spannen naar den maatstaf van 1 HA. per dag per jaar 250 HA. oogst in totaal wordt geproduceerd, dan komen per HA. de energiekosten dus op $f 2,40$. Dit is het geval bij een hoeve van 150 HA. bedrijfsoppervlakte. Is de bedrijfsoppervlakte kleiner, dan stijgen deze kosten omgekeerd evenredig, doch komen praktisch niet boven het dubbele, dus $f 4,80$, uit, wat nog een zeer laag bedrag is.

Door het opleveren van deze bedrijfsnormen heeft de proefneming aangetoond, dat de werkwijze technisch en economisch geheel beantwoordt aan den eisch en de verwachting.

Voor het tweede gedeelte van de proefneming, nl. de verwezenlijking van de gebleken mogelijkheid in een loonend duurzaam bedrijf, is het verloop niet zoo fortuinlijk geweest, in dien zin, dat het nog niet zoover gebracht is kunnen worden, hoofzakelijk omdat niet de vereischte oppervlakte vruchtdragende grond kon worden ontgonnen en ingericht.

Voor het verkrijgen van een loonend bedrijf moeten in de eerste plaats twee hoofdeischen vervuld zijn:

le. beschikking over de minimum benoodigde oppervlakte ont- 
gonnen en geakkerden vruchtdragenden grond, om genoegzame oogst te produceeren;

2e. volledige beheersching van de technische factoren van het bedrijf door voldongen inrichting van het terrein, zoodat geen onvolkomenheden de vlotte gang van het werk kunnen bemoeilijken, en evenzoo voldoende en passende outilleering.

Aan beide eischen kon nog niet worden voldaan, eenerzijds door een reeks onfortuinlijkheden, anderzijds door onvoldoende tijd en middelen. Tal van bijkomende factoren, onvermijdelijkheden van de oriënteeringsperiode en de detailexperimenten, hebben eveneens een vertragenden invloed uitgeoefend.

Bij den opzet van de onderneming was erop gerekend in Suriname een terreinstuk te zullen aantreffen, dat reeds in een zoodanigen toestand van gevorderde ontginning en inrichting verkeerde, dat daarop zonder veel voorbereiding dadelijk op de gedachte werkwijze de regelmatige bedrijfsbewerkingen zouden kunnen worden toegepast.

Bij aankomst in Suriname bleek het beoogde terrein in geenen deele aan deze verwachting te beantwoorden. Noodgedwongen moest begonnen worden op een terrein, waarop volledig ontginnings- en inrichtingswerk moest worden uitgevoerd. Het eerste begin, omstreeks midden April 1934, viel zeer laat in het plantseizoen voor rijst, terwijl 1934 bijzonder slechte weersconditiën voor het rijstgewas opleverde, zoodat over geheel Suriname de rijstoogst voor $60 \%$ mislukte. ${ }^{1}$ )

De aangekochte ossen bleken voor het grootste gedeelte inferieur en verkeerden in zeer deplorabelen fysieken toestand, waardoor hunne energiecapaciteit ver beneden den eisch bleef.

De medegebrachte werktuigen konden door een en ander niet met het noodige effect benut worden.

Ook de zeer groote wisselvalligheid van het weer, met onberekenbare variaties, geheel afwijkende van het gemiddelde seizoenbeeld in de traditioneele jaargetijden, leverde schadelijke en de vordering remmende verrassingen op, in het bijzonder de zware, aanhoudende regens gedurende de kleine-drogetijds-maanden Maart-April 1936.

1) De productie in Suriname van gepelde rijst $160 \%$ van de padiproductie) bedroeg in de jaren:

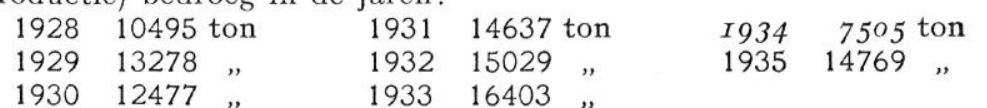

$193012477, \quad 1933 \quad 16403$,

Deze cijfers zijn ontleend aan het artikel „Gegevens over de rijstsituatie" van S. B. in De West van 23 October 1936. 
Al dergelijke hindernissen en moeilijkheden, niet van blijvenden of beslissenden aard zijnde, hebben de voortgang echter niet kunnen stuiten, werden successievelijk overwonnen of omzeild, en teekenen als zoovele mijlpalen de gestadige vordering af.

Gedurende de jaren 1934/35 werd hoofdzakelijk gewerkt op de terreinen in den Coms. Simonspolder nabij Station Domburg en op een terreinstuk van een oude plantage aan de Saramaccarivier. Op beide terreinen bleken de cultuurcondities zeer ongeschikt voor het doel.

Het mede verkende terrein van den ,polder achter Adrichem” nabij Station Domburg beantwoordde tenslotte in zeer bevredigende mate; het vereischt echter meer werk voor de ontginning.

In totaal werd in 1934/35 op de twee eerstgenoemde terreinen $65 \mathrm{HA}$. in ontginningsbewerking genomen. Op deze terreinen werden slechts zeer schrale oogsten gewonnen, die een kleine fractie van de kosten goed maakten. $55 \mathrm{HA}$. werd daarvan wegens gebleken ongeschiktheid weer prijsgegeven, zoodat geld en arbeid, daaraan besteed, praktisch geheel teloor gegaan zijn. De grond is goed genoeg, het hapert slechts aan de cultuurconditie, doch de werken ter verbetering daarvan vereischen teveel uitgaven en tijd.

Slechts de $10 \mathrm{HA}$. in de Coms. Simonspolder, waaraan het meeste werk besteeds was, is aangehouden, doch is nog slechts als minderwaardige akker te waardeeren. Bovendien was op het terrein „achter Adrichem” een oppervlakte van ca. $11 \mathrm{HA}$. ter verkenning bewerkt en geschikt bevonden.

Ten derde male opnieuw begonnen, werd in 1936 op het terrein van den polder achter Adrichem $35 \mathrm{HA}$. in aanplant gebracht, waarvan ca. $10 \mathrm{HA}$. zonder grondbewerking.

Het loopende jaar is dan ook te beschowwen als eerste serieus beginjaar van de ontginning voor het eigenlijke hoevebedrijt.

De verkregen opbrengsten van de geslaagde stukken op dit terrein varieeren van $2500 \mathrm{KG}$. tot $5000 \mathrm{KG}$. droge padikorrel per HA., afhankelijk van padivarieteit en beplantingsdichtheid.

Ware met wat meer geluk van den aanvang af in 1934 op dit goede terrein begonnen, dan zou daarop thans stellig meer dan de dubbele oppervlakte, en wel ca. $80 \mathrm{HA}$., ontgonnen zijn en daarmede het loonende bedrijf tevens gevestigd zijn. Deze positie is reeds het volgende jaar te bereiken, indien de beschikking kan worden verkregen over de noodige geldmiddelen voor de uitbreiding van de ontginning tot 60 à $70 \mathrm{HA}$. 
Het resultaat van de proefneming is kort samengevat dus:

$a$. de gekozen werkwijze is al dadelijk praktisch goed uitvoerbaar, soepel aanpasbaar en een loonende productie mogelijk makende gebleken;

$b$. de keuze van den grond is aanvankelijk minder voorspoedig geslaagd, zoodat dientengevolge een financieel succes is belemmerd, doch ten slotte is geschikt terrein getroffen voor het opbouwen van een hoevebedrijf, en de toestand is bereikt, dat voortgaande het bedrijf reeds met den volgenden oogst een loonende uitkomst kan opleveren.

Aan de proefneming als zoodanig is al het beschikbare geld besteed moeten worden, zoodat voor het voortzetten van het werk en de omzetting in een bedrijf, aanvulling met nieuw kapitaal noodig is.

De economische beteekenis van deze proefneming voor Suriname is, dat zij het bestaan en het openliggen vastgesteld heeft van een korten weg voor Suriname, om zich uit de geslachten-lange economische nood te verheffen en zijne welvaart en sociale ontwikkeling te grondvesten op duurzame vaste basis.

Suriname biedt voor de rijstcultuur buitengewoon gunstige voorwaarden door zijne grooteoppervlaktevan onbenutten vruchtbaren grond, die bij extensieve cultuur oogsten aan padi oplevert, dubbel zoo groot als op Java en even groot als elders slechts bij zeer intensieve cultuur en zware bemesting te verkrijgen is; overvloed van voor irrigatie gemakkelijk benutbaar, slibrijk, zoet rivierwater en klimaatsconditien, die een buitengewoon langen planttijd voor de rijst van 6 maanden achtereen mogelijk maken.

De kostprijs van $100 \mathrm{KG}$. exportrijst zal op ongeveer $f 2,50$ uitkomen, zoodat Suriname tot de volstrekt goedkoopste productengebieden van rijst behoort en dientengevolge tegen elke vrije concurrentie tot het laatste toe opgewassen zal zijn.

Rijst als wereldmarkt-product heeft het karakter van halfbewerkte grondstof en daaraan worden slechts soorteischen gesteld, en eischen van behoorlijke homogene sorteering en voldoende afwerking. Aan deze eischen is zonder eenige moeite te voldoen; zij zijn van zuiver mechanischen aard, de twee laatste zijn kwesties van toepassing van een behoorlijke volledige pelmolen.

Voor verscheping is geen enkele bijzondere voorziening noodig, en aangezien rijst spoedig in zeer groote kwanta ter verscheping aangeboden kan worden, zal het niet veel moeite kosten om concurreerende vrachttarieven te verkrijgen. 
De eenige beperking bij de verhandeling leveren de beschermingsmaatregelen van verschillende consumptielanden voor het product uit eigen gebieden op. Doch in de praktijk heeft dat geen beteekenis voor Suriname, daar er twee belangrijke consumptiegebieden aanwezig zijn, ten opzichte waarvan Suriname bijzonder gunstig gelegen is, waar de Surinaamsche rijst in volkomen gelijke conditie met andere mededingers altijd een vrije markt zal vinden met praktisch voor Suriname ongelimiteerde afzetgelegenheid, n.l. Nederland en Cuba, elk met een jaarlijksche behoefte aan rijst van ca. 170.000 ton en 200.000 ton, dus 370.000 ton te zamen.

Cuba neemt hoofdzakelijk rijst van de goedkoopere klassen op, waarvan „Siam Super” de standaard aangeeft, een rijstsoort geheel overeenkomende met rijst van de padi Tjina, de Skrivimankoti en de Berbico, alle drie zeer gemakkelijke en rijk dragende soorten hier in Suriname.

De wereldmarktnoteering voor ,Siam Super” schommelt thans tusschen de $f 6,50$ en $f 7,50$ per $100 \mathrm{KG}$. cif haven van bestemming.

Het grootste deel van de door Nederland opgenomen rijst behoort ook tot deze goedkoope prijsklassen, echter met een ruimere schaalverdeeling in kwaliteiten en prijzen, schommelende tusschen $f 6,50$ en $f 9$. - per $100 \mathrm{KG}$. cif. Daarnaast bestaat echter een belangrijke vraag naar superieure soorten, speciaal van het Javatype, welke niet geheel bevredigd kan worden door de tegenwoordige producenten. Voor deze rijstsoorten wordt $f 10$,- - tot $f 12$,per $100 \mathrm{KG}$. cif betaald.

Indien een redelijk vrachttarief voor den uitvoer van rijst van Suriname naar die twee groote markten kan worden verkregen, hoogstens gelijk aan de vracht van rijst van Burma (Rangoon) en Siam (Bangkok) daarheen, dan kan Suriname in zeer sterke positie de concurrentie opnemen met de andere rijstproducenten, onder welke ook Brazilië, Mexico, de Ver. Staten van N. A. en Japan.

Thans kan Suriname hoogstens 5000 à 6000 ton boven de eigen behoefte voor export produceeren, terwijl de twee genoemde afzetgebieden een opnamecapaciteit van te zamen 370.000 ton hebben. Indien Suriname bv. slechts $25 \%$ hiervan kan veroveren, dan beteekent dit, dat 500 rijsthoeven van 100 HA. padi-aanplant-oppervlakte cum anexis een welvarend bestaan kunnen vinden, jaarlijks een uitvoerwaarde van 6 tot 8 miljoen gulden alleen aan rijst, boven hetgeen thans uitgevoerd wordt, opbrengen.

Gesteund op dit soliede hoofdbedrijf, dat reeds voorziet in de algemeene bedrijfskosten, kunnen tal van producten, die thans 
als zelfstandig hoofdbedrijf niet loonend te procudeeren zijn of de belemmering van allerlei duurmakende verhandelingseischen ondervinden, in nevenbedrijf voortgebracht, met voordeel verhandeld worden, bv. arabica koffie, sinaasappelen, eventueel ook ananas en bacoven.

De kleinlandbouwer kan gemakkelijk ingeschakeld worden door een deel van zijn oppervlakte te doen beplanten met hoogwaardige rijstvarieteiten, die door de exporthoeven of de speciale exportpellers tegen loonenden prijs kunnen worden opgekocht. Hierdoor zal tevens de binnenlandsche markt van rijst voor den kleinlandbouwer tot loonend niveau kunnen stijgen, doordat het drukkende overschot wordt afgevloeid.

De rijstcultuur verwezenlijkt ook de mogelijkheid tot passende voortontwikkeling van Suriname als echte vestigingskolonie, de eenige toekomstmogelijkheid voor dit leege land.

Want een rijsthoeve kan in coöperatieve samenwerking van Europeesche (ook Surinaamsche overigens) kolonisten gedreven worden en geleidelijk tot zoodanige uitbreiding gebracht worden, dat afsplitsing in zelfstandige hoeven voor elk lid van de samenwerkende groep mogelijk is.

Alle cultuurwerk en het ambachtswerk kan, zooals de dagelijksche praktijk van de proefneming afdoende uitwijst, zonder eenig bezwaar of schade voor den Europeeschen kolonist, ja zelfs als gezonde, stimuleerende occupatie, door deze zelf gedaan worden. Het klimaat van Suriname levert geen enkel bezwaar op; het is een aangenaam, gezond en mild tropenklimaat, waarvan de warmte nooit overmatig is en de koele nachten, zoo mede de bijzonder aangename subtropische maanden December tot April, met minimum nacht- en maximum dagtemperaturen van $60^{\circ}$ en $78^{\circ}$ F. ${ }^{1}$ ), gezonde verkwikking brengen.

Alleen voor het zware delfwerk, boschontginningswerk en de weinig affectieve werkzaamheden, die in handenarbeid moeten geschieden, is het employeeren van inlandsche arbeidskrachten noodig.

De rijstcultuur maakt het dus mogelijk dat reeds met een betrek-

1) Deze temperaturen gelden niet voor Paramaribo, een anachronisme als tropenstad, waar men nog steeds bouwt op dezelfde wijze, als bij den oorspronkelijken aanleg, omstreeks het midden van de $17 \mathrm{e}$ eeuw, en waarvan de gesloten rijen houten huizen met meestal zinken daken vlak langs de straat, een ware zonnewarmte-accumulator overdag en radiator 's avonds en 's nachts vormen, zoodat het daar altijd eenige graden warmer is dan „buiten” of „op plantage”. 
kelijk kleine kapitaalinbreng van ca. $f$ 5000,- per man (bij aansluiting aan het bestaande aanvangsbedrijf kan dit voor een eerste groep kolonisten reeds met beduidend minder geld) voor flinke Europeesche (Surinaamsche) krachten de kans verzekerd kan worden, om het tot een zelfstandig en redelijk welvarend bestaan naar Europeeschen maatstaf te brengen, terwijl niets aan dezulken met wijderen vleugelslag in de weg staat, om dan nog verder te rijzen.

Een goed georganiseerde systematische kolonisatie onder ervaren leiding van groepen van 10 tot 12 kolonisten, die met $f 50000$ à $f 60000,-$ kapitaal een hoeve van 150 HA. opzetten en samen bewerken, heeft aldus bij degelijke inspanning en goede samenwerking van de kolonisten en vast besloten doorzettingswil een zeer goede praktische kans van slagen.

In het algemeen belang, zoowel van Nederland als van Suriname, mag een eerste poging niet onbeproefd gelaten worden en op de verwezenlijking van dit praktische gevolg van de proefneming wordt thans het streven gericht.

Een ieder, die belang stelt in Suriname, hetzij uit nationaal gemeenschapsgevoel of om meer directe verbondenheid van persoon en belangen met dit land, weet, dat de reeds in de tweede helft van de 18 e eeuw begonnen likwidatie van de welvarende kolonie van weleer thans voldongen is: Suriname is thans economisch - en ook sociaal - volkomen aan den grond en men staat hier voor de noodzakelijkheid van een nieuw begin.

De boven samengevatte beschouwingen over de proefneming van de Suriname Hoeve Maatschappij bevestigen de meening, dat er geen meer belovende richting is, dan die daarmede is ingeslagen en wordt aanbevolen, om werkelijk tot een spoedig nuttig resultaat voor de afdoende verbetering van den economischen toestand van Suriname te geraken, hetgeen dan ook vanzelf tot verbetering van de sociale toestanden zal leiden.

Men lette erop hoe velerlei moeilijkheden de andere nagestreefde oplossingen in den weg staan, die men hier niet in de hand heeft: voor koffie de smaak en de voorkeur van het consumeerende publiek en de absolute markt- en prijsbeheersching door Brazilië, voor bacoven de concurreerende belangen van de bij de productie en verhandeling betrokken kapitaalmachten en de verschepingseischen; voor sinaasappelen de verpakkings- en verschepingseischen en de buitengewone invloed van de geldwaardeschommelingen en manipulaties.

Voor rijst bestaan zulke bezwaren niet. Er zijn geen speciale 
verschepingsvoorzieningen vereischt, terwijl de invloed van geldwaarde-schommelingen zich volkomen evenredig doet gelden en gelijkelijk, dus compenseerend, werkt op kosten en opbrengsten, terwijl rijst voorts volkomen onbeïnvloede concurrentie-gelegenheid vindt op twee zoo gunstig gelegen afzetmarkten in Nederland en Cuba.

De Suriname Hoeve Maatschappij is met haar werk genaderd tot de grens, dat het volgende jaar de proef op de som zou kunnen worden genomen, door een eerste verscheping van een beduidende hoeveelheid rijst naar Nederland, terwijl door monsterbeoordeeling zekerheid is verkregen, dat de te verschepen rijsten geschikt zijn voor de Nederlandsche markt en in de hoogste prijsklassen concurreerend zullen kunnen worden aangeboden.

Om dit te kunnen doen heeft de Suriname Hoeve Maatschappij eenige hulp noodig voor aankoop van betere ossen ter vervanging en aanvulling van de inferieure dieren, waarmede zij van den beginne af opgescheept zit, ter aanvulling van de outillage, overeenkomstig de in de praktijk gebleken behoefte, voor ontginning van voldoende aanplant-oppervlakte, benevens eenig werkkapitaal, m.a.w. ten einde de zwakke proefnemingsopzet om te zetten in een eerste deugdelijk geoutilleerd en gefundeerd definitief hoevebedrijf.

De volgende aanhaling uit het verzoek om medewerking, opgenomen in de oprichtingscirculaire van de Suriname Hoeve Maatschappij kan in dit verband wellicht met nut gememoreerd worden:

„... het kapitaal .... zoo krap gemeten is, dat het .... ,,zeer weinig speelruimte overlaat, om een toevallige bijzon„,dere cumulatie van natuurlijke risicos op te vangen, welke, , ,indien zich voordoende bij de begin-moeilijkheden, welke „, bij zoo volkomen nieuwe werkwijze vanzelf reeds grooter „zullen zijn, dan wanneer het gaat om het opzetten van een „bedrijf, waarvan de normen reeds in de praktijk bepaald en „gestabiliseerd zijn, buitengewone eischen aan het finan„cieele en materieele weerstandsvermogen van ons, onder„nemers, zal stellen.

„Wij gaan zonder eenige wijfeling, met het vaste besluit „door te zetten en vol te houden onder het stimuleerend de„vies WIL EN WIN. Niettemin zullen wij hulp van dezulken, „die belang stellen in ons initiatief en onze aanpakdurf en "ons de taak wat vergemakkelijken willen, ten zeerste op prijs "stellen."

West-Indische Gids XVIII 
Dit beroep werd geëindigd met de woorden:

„Wij wagen het, pakken aan en willen winnen. Staat gij „ons bij en helpt ons winnen in het belang van Suriname en "Nederland."

Met groote erkentelijkheid kan worden verklaard, dat in belangrijke mate medewerking en hulp zijn ontvangen door de Suriname Hoeve Maatschappij, zoowel van Regeering en Bestuur als van particuliere zijde in Nederland en - het wordt met bijzondere voldoening geconstateerd - vooral in Suriname.

Afzonderlijk en met warme vereering en dankbaarheid wordt de gift gememoreerd van wijlen Hare Majesteit Koningin EMMA „.... uitsluitend bedoeld als blijk van waardeering van „Hare Majesteit voor de poging, om met de onderneming „Suriname Hoeve Maatschappij”. . . . een proef in Suriname „te wagen.

„Hare Majesteit hoopt ten zeerste, dat deze moedige po"ging moge slagen ten spijt van de ongunst der tijden."

Deze hartelijke woorden, getuigende van zoo volkomen juist aanvoelen van den aard van het werk en van den geest, waarin het werd aangevat en begonnen, verleende aan Hare nobele geste oneindige waarde voor de ondernemers en is voor hen een voortdurende aanvuring geweest.

Door die hulp van vele kanten is het gelukt, om ondanks de vertwijfelend gestadige opvolging van ongewone pechomstandigheden vol te houden en het te brengen tot de grens van het zekere slagen, ook wat aangaat de financieele bedrijfsuitkomst.

Die hulp is dus nog niet geheel voldoende gebleken.

Opnieuw wordt getracht hen, die sympathie hebben voor de poging en het belang en de beteekenis daarvan inzien en erkennen, te bereiken en hunne daadwerkelijke steun en medewerking te verwerven, om de laatste moeilijkheden te overkomen, welke nog scheiden van het uiteindelijke volledige succes. Het gaat om een samenwerking tot bereiking van een doel, dat, voortgezet doorwerkende, algemeene zegen zal verspreiden.

De initiatiefnemers hèbben aangepakt, zij hebben met volledige, onverslapte toewijding zich geheel gegeven in persoon en goed aan de taak, welke de algemeene zaak in zoo belangrijke mate dient. Wat zij aan hulp behoeven, kan verkregen worden door naar verhouding luttele individueele bijdragen.

Station Domburg Paramaribo. (Suriname). 